\title{
A novel nomogram to predict the overall survival of patients with colloid adenocarcinoma of the lung
}

\author{
Jun Zhang^, Deruo Liu \\ Department of Thoracic Surgery, Peking University China-Japan Friendship School of Clinical Medicine, Beijing, China \\ Contributions: (I) Conception and design: J Zhang; (II) Administrative support: D Liu; (III) Provision of study materials or patients: All authors; (IV) \\ Collection and assembly of data: J Zhang; (V) Data analysis and interpretation: J Zhang; (VI) Manuscript writing: All authors; (VII) Final approval of \\ manuscript: All authors. \\ Correspondence to: Deruo Liu. Department of Thoracic Surgery, Peking University China-Japan Friendship School of Clinical Medicine, No. 2, East \\ Yinghua Street, Chaoyang District, Beijing 100029, China. Email: deruoliu@163.com.
}

Background: Colloid adenocarcinoma of the lung is one of rare subtypes of pulmonary adenocarcinoma.
The purpose of our study is to establish a predictive model for the overall survival of colloid adenocarcinoma.
Methods: A total of 749 patients were separated from the Surveillance, Epidemiology, and End Results
database between 2011 and 2015 . Cox regression was performed to select the predictors of overall survival.
The calibration curves, concordance index, the receiver operating characteristic curve, and the area under
the curve were used to verify the nomogram. Kaplan-Meier curves were used to illustrate and compare the
overall survival of patients in different surgical groups. Results: Multivariate analyses demonstrated clinical characteristics such as age, sex, race, site, tumor stage, stage $T$, metastatic sites at diagnosis, surgical treatment were associated with prognosis. In the nomogram, we could predict the probability of overall survival for patients. The concordance index of the novel nomogram was 0.849 , which meant that the model had a good discriminated ability. A good consistency was indicated by the calibration curves in the probability of 1-, 3-, and 5-year overall survival between the actual observation and the nomogram prediction. We plotted the receiver operating characteristic curve and the area under the curve was $0.905,0.923,0.885$, respectively. The Kaplan-Meier curves indicated that overall survival was precisely distinguished by the different surgical status. The survival rate of patients in the surgery group was significantly higher than that of patients without surgery $(\mathrm{P}<0.0001)$. Segmentectomy had the highest survival rate than the lobectomy and wedge resection $(\mathrm{P}=0.0122)$.

Conclusions: We constructed and validated a nomogram to help predict overall survival for colloid adenocarcinoma. Clinicians could predict individualized survival and give treatment recommendations.

Keywords: Submitted Aug 27, 2020. Accepted for publication Dec 17, 2020.

Submitted Aug 27, 2020. Accepted for publication Dec 17, 2020.

doi: $10.21037 /$ tcr-20-2795

View this article at: http://dx.doi.org/10.21037/tcr-20-2795

\section{Introduction}

Colloid adenocarcinoma is one of uncommon variants of lung adenocarcinoma that accounts for about $0.24 \%$ of all primary lung cancers (1). Colloid adenocarcinoma shows extracellular mucin in abundant pools, which distend alveolar spaces with the destruction of their walls (2). Cystic mucinous adenocarcinoma, mucinous cystadenoma, mucinous cystic tumor, cystic mucinous adenocarcinoma and so on were what it used to be called in the old days (3-9). In 2011, colloid adenocarcinoma was described as

\footnotetext{
^ ORCID: 0000-0001-7320-8206.
} 
a variant of adenocarcinoma (2). Because this tumor is rare, only some case reports are reported. The therapeutic recommendations and the risk factors of survival are difficult to understand. This study aims to establish a prognosis prediction model to predict the overall survival of colloid adenocarcinoma by using the Surveillance, Epidemiology, and End Results database.

We present the following article in accordance with the TRIPOD reporting checklist (available at http://dx.doi. org/10.21037/tcr-20-2795).

\section{Methods}

\section{Study population}

SEER 18 population-based cancer Registries (1975 to 2017 dataset) were chosen to select patients, which is maintained by the National Cancer Institute and covers nearly $28 \%$ of the population in the United States. We strictly grasp the inclusion and exclusion criteria of research objects to ensure good representativeness a collect as much data as possible on objective indicators. The inclusion criteria in our study were (I) patients with lung cancer was colloid adenocarcinoma diagnosed between 2011 and 2015; (II) patients aged 18 years or older who were diagnosed; (III) the information of patient consisted of the age of diagnosis, race, sex, primary site, TNM stage, tumor staging, the pattern of distant metastasis, surgical method, survival status and time. Individuals who had unclear information were subsequently excluded. The demographic data of all eligible cases were collected and retrospectively analyzed.

The study was conducted in accordance with the Declaration of Helsinki (as revised in 2013). This article does not contain any studies with human participants or animals performed by any of the authors. All procedures performed in study involving human data were extracted freely from the SEER Research Data available to the public online (https://seer.cancer.gov/data/access.html).

\section{Statistical analysis}

An analysis on Cox regression was implemented in order to assess the risk factors of overall survival. It was set up in that $\mathrm{P}<0.05$ was considered statistically significant. $\mathrm{R}$ software was used to set up a nomogram based on the numerous possible prognostic factors which could be associated with the overall survival. The validation of the nomogram was executed, and the results were evaluated based on the concordance index, the receiver operating characteristic curve, the area under the curve and calibration curves. The concordance index, receiver operating characteristic curve and the area under the curve were used to denote the predictive accuracy and differentiation ability of each factor of the nomogram. Calibration curves $(1,000$ bootstrap resamples) were performed to check the calibration of the nomogram. Kaplan-Meier curves were used to illustrate and compare the overall survival of patients in the different surgical groups. Data extraction was collected using the version 8.3.6.1 of SEER*Stat software and data analyses were all performed using $\mathrm{R}$ software (version 4.0.0).

\section{Results}

\section{Demographics}

Overall, 749 patients with colloid adenocarcinoma of the Lung were included among which $373(49.80 \%)$ patients were diagnosed at the age of $\geq 70$ years. Females accounted for $54.34 \%$ and the majority of patients were White $(81.98 \%)$ which is related to the fact that the United States is a white-dominated country. In terms of the primary site, the percentages of the upper lobe and lower lobe were $39.92 \%$ and $49.67 \%$ respectively. For the stage, the stage IA and IV had a higher proportion $(31.64 \%, 28.57 \%$, respectively). According to the AJCC guidelines for the staging of tumor nodule metastasis (TNM), T1a, T2a, and $\mathrm{T} 3 \mathrm{had}$ a higher proportion than others. For lymph nodes, N0 $(73.97 \%)$ is the most common. For the pattern of the distant metastasis, bone metastasis is more common than the brain and liver. More than half of the patients underwent surgery (Table 1).

\section{Cox regression analysis for estimating the risk factors of overall survival}

Cox proportional hazards model was used to evaluate the role of each variable in predicting overall survival. Multivariate analyses demonstrated that the clinical characteristics such as such as age, sex, race, primary site, tumor staging, stage $\mathrm{T}$, metastatic sites, surgical treatment were connected with the prognosis of patients (Table 2).

\section{Building and validating the novel nomogram}

We established a prognosis prediction model which 
Table 1 Clinicopathologic characteristics of the entire cohort of patients $(\mathrm{n}=749)$

\begin{tabular}{|c|c|}
\hline Characteristics & Number (\%) \\
\hline \multicolumn{2}{|l|}{ Age (years) } \\
\hline$<70$ & $376(50.20)$ \\
\hline$\geq 70$ & $373(49.80)$ \\
\hline \multicolumn{2}{|l|}{ Race } \\
\hline White & $614(81.98)$ \\
\hline Black & 75 (10.01) \\
\hline Other & $60(8.01)$ \\
\hline \multicolumn{2}{|l|}{ Sex } \\
\hline Female & 407 (54.34) \\
\hline Male & $342(45.66)$ \\
\hline \multicolumn{2}{|l|}{ Site } \\
\hline Upper lobe & 299 (39.92) \\
\hline Middle lobe & $43(5.74)$ \\
\hline Lower lobe & $372(49.67)$ \\
\hline Other lobes & $35(4.67)$ \\
\hline \multicolumn{2}{|l|}{ Stage } \\
\hline IA & 237 (31.64) \\
\hline IB & $111(14.82)$ \\
\hline IIA & $44(5.87)$ \\
\hline IIB & 82 (10.95) \\
\hline IIIA & $53(7.08)$ \\
\hline IIIB & $8(1.07)$ \\
\hline IV & $214(28.57)$ \\
\hline \multicolumn{2}{|l|}{$\mathrm{T}$} \\
\hline T1a & $179(23.90)$ \\
\hline $\mathrm{T} 1 \mathrm{~b}$ & $100(13.35)$ \\
\hline $\mathrm{T} 2 \mathrm{a}$ & $172(22.96)$ \\
\hline T2b & $50(6.68)$ \\
\hline T3 & 157 (20.96) \\
\hline $\mathrm{T} 4$ & $91(12.15)$ \\
\hline \multicolumn{2}{|l|}{$\mathrm{N}$} \\
\hline No & 554 (73.97) \\
\hline $\mathrm{N} 1$ & $43(5.74)$ \\
\hline N2 & 109 (14.55) \\
\hline N3 & $43(5.74)$ \\
\hline
\end{tabular}

Table 1 (continued)
Table 1 (continued)

\begin{tabular}{lc}
\hline Characteristics & Number (\%) \\
\hline Bone metastasis & $101(13.48)$ \\
Yes & $648(86.52)$ \\
No & \\
Brain metastasis & $43(5.74)$ \\
Yes & $706(94.26)$ \\
No & \\
Liver metastasis & $17(2.27)$ \\
Yes & $732(97.73)$ \\
No & \\
Surgery & $124(16.56)$ \\
Wedge resection & $13(1.74)$ \\
Segmentectomy & $291(38.85)$ \\
Lobectomy & $321(42.86)$ \\
No &
\end{tabular}

including above factors (Figure 1). In the nomogram, each predictor was granted a score on a points scale. By adding the total predicted scores on the bottom scale, we could predict the overall survival in patients with colloid adenocarcinoma of the Lung. The concordance index of the novel nomogram was 0.849 , which meant that the model had a good discriminated ability. A good consistency was indicated by the calibration curves in the probability of 1-, 3-, and 5-year overall survival between the actual observation and the nomogram prediction (Figure 2). We also drew the receiver operating characteristic curve of the 1-, 3-, and 5-year overall survival, and the area under the curve were $0.905,0.923,0.885$ respectively, which also demonstrated good discrimination (Figure 3).

\section{Kaplan-Meier curves of overall survival for patients in the different surgical status}

The Kaplan-Meier curves indicated that overall survival in the different surgical status was precisely distinguished. The survival rate of patients in the surgery group was significantly higher than that of patients without surgery $(\mathrm{P}<0.0001)$. Among surgical procedures, segmentectomy has the highest survival rate than the lobectomy and wedge resection ( $\mathrm{P}=0.0122)$ (Figure 4). 
Table 2 Cox regression analysis for estimating the risk factors of overall survival

\begin{tabular}{|c|c|c|c|}
\hline Variable & Hazard ratio & $95 \% \mathrm{Cl}$ & $P$ value \\
\hline$<70$ & Reference & & \\
\hline$\geq 70$ & 1.333 & $1.0514-1.6907$ & 0.018 \\
\hline \multicolumn{4}{|l|}{ Race } \\
\hline Black & 0.913 & $0.6009-1.3885$ & 0.672 \\
\hline Other & 0.566 & $0.3422-0.9364$ & 0.027 \\
\hline \multicolumn{4}{|l|}{ Sex } \\
\hline Female & Reference & & \\
\hline Upper lobe & Reference & & \\
\hline Middle lobe & 1.845 & $1.0927-3.1158$ & 0.022 \\
\hline Lower lobe & 1.231 & $0.9617-1.5749$ & 0.099 \\
\hline Other lobe & 1.821 & $1.1562-2.8694$ & 0.010 \\
\hline \multicolumn{4}{|l|}{ Stage } \\
\hline IA & Reference & & \\
\hline IB & 1.054 & $0.4753-2.3351$ & 0.898 \\
\hline$\| A$ & 2.126 & $0.9664-4.6771$ & 0.061 \\
\hline \multicolumn{4}{|l|}{$\mathrm{T}$} \\
\hline T1a & Reference & & \\
\hline $\mathrm{T} 1 \mathrm{~b}$ & 1.132 & $0.6612-1.9374$ & 0.652 \\
\hline $\mathrm{T} 2 \mathrm{a}$ & 1.219 & $0.6874-2.1628$ & 0.498 \\
\hline $\mathrm{T} 2 \mathrm{~b}$ & 2.109 & $1.0739-4.1401$ & 0.030 \\
\hline T3 & 1.215 & $0.6964-2.1186$ & 0.493 \\
\hline $\mathrm{T} 4$ & 1.337 & $0.7775-2.2987$ & 0.294 \\
\hline \multicolumn{4}{|l|}{$\mathrm{N}$} \\
\hline No & Reference & & \\
\hline N1 & 1.420 & $0.8874-2.2730$ & 0.144 \\
\hline N2 & 1.222 & $0.8883-1.6796$ & 0.218 \\
\hline N3 & 0.956 & $0.6080-1.5019$ & 0.218 \\
\hline
\end{tabular}

Table 2 (continued) 
Table 2 (continued)

\begin{tabular}{|c|c|c|c|}
\hline Variable & Hazard ratio & $95 \% \mathrm{Cl}$ & $P$ value \\
\hline \multicolumn{4}{|c|}{ Bone metastasis } \\
\hline Yes & Reference & & \\
\hline No & 0.576 & $0.4218-0.7871$ & $<0.001$ \\
\hline \multicolumn{4}{|c|}{ Brain metastasis } \\
\hline No & 0.607 & $0.4164-0.8836$ & 0.009 \\
\hline \multicolumn{4}{|c|}{ Liver metastasis } \\
\hline Yes & Reference & & \\
\hline No & 0.728 & $0.4214-1.2580$ & 0.255 \\
\hline No & 2.892 & $2.1123-3.9588$ & $<0.001$ \\
\hline
\end{tabular}

Points
Age
Race
Sex
Site
Stage
T
N
Bone
Brain
Liver
Surgery
Total points
1-year survival probability
3-year survival probability
5-year survival probability

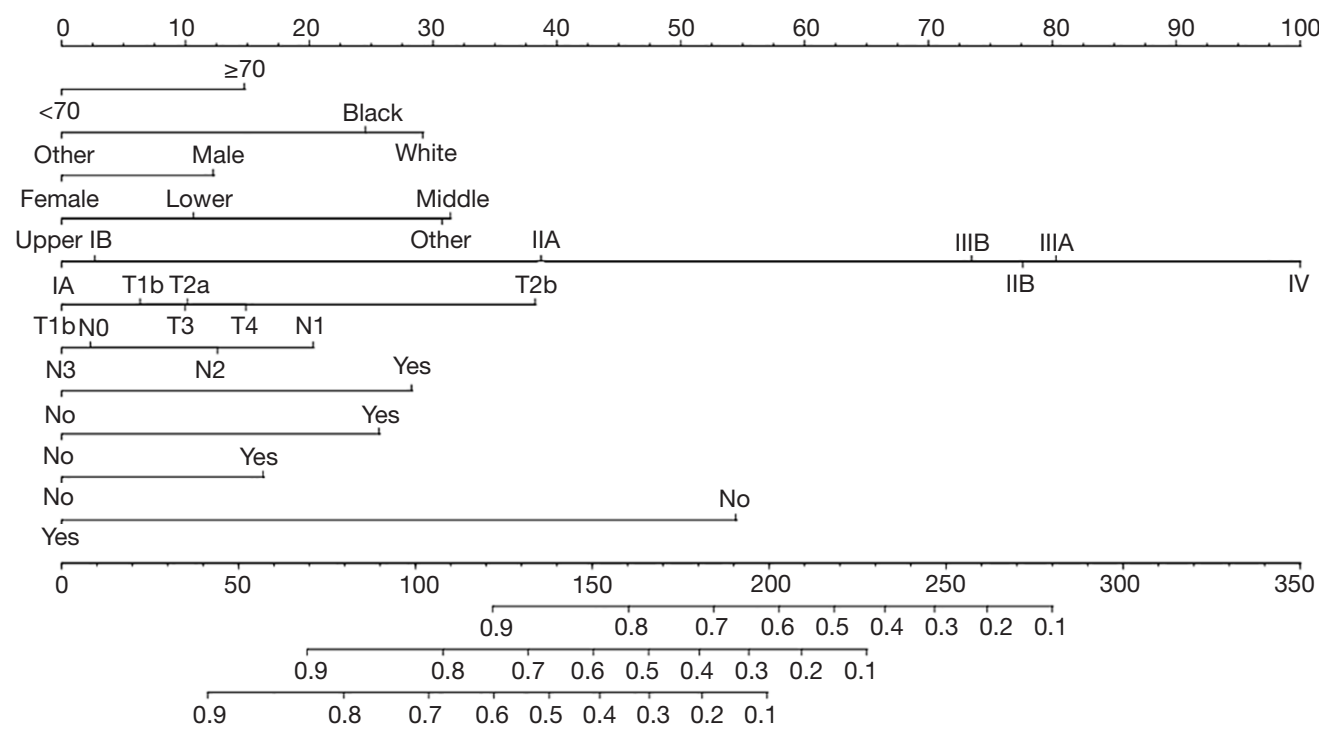

Figure 1 Nomogram to predict the overall survival of patients with colloid adenocarcinoma of lung.

\section{Discussion}

Colloid adenocarcinoma of the lung is one of extremely rare subtypes of pulmonary adenocarcinoma (10). Cough, hemoptysis, and thoracalgia are the most common clinical manifestations. But some are asymptomatic which is often detected on a routine health examination (11). In reported series, colloid adenocarcinoma was observed more frequently in females, the finding was like ours. Tateishi et al. showed that there was a higher rate of metastasis in the colloid adenocarcinoma than other types of lung cancer, including the pulmonary, lymph node, and hematogenous metastasis (12). But in our study, compared with other lung cancers, colloid adenocarcinoma had a similar metastatic frequency. Some reports have described the discoveries of low attenuation and poor enhancement on contrast CT, low intensity on T1WI, and high intensity on T2WI on 

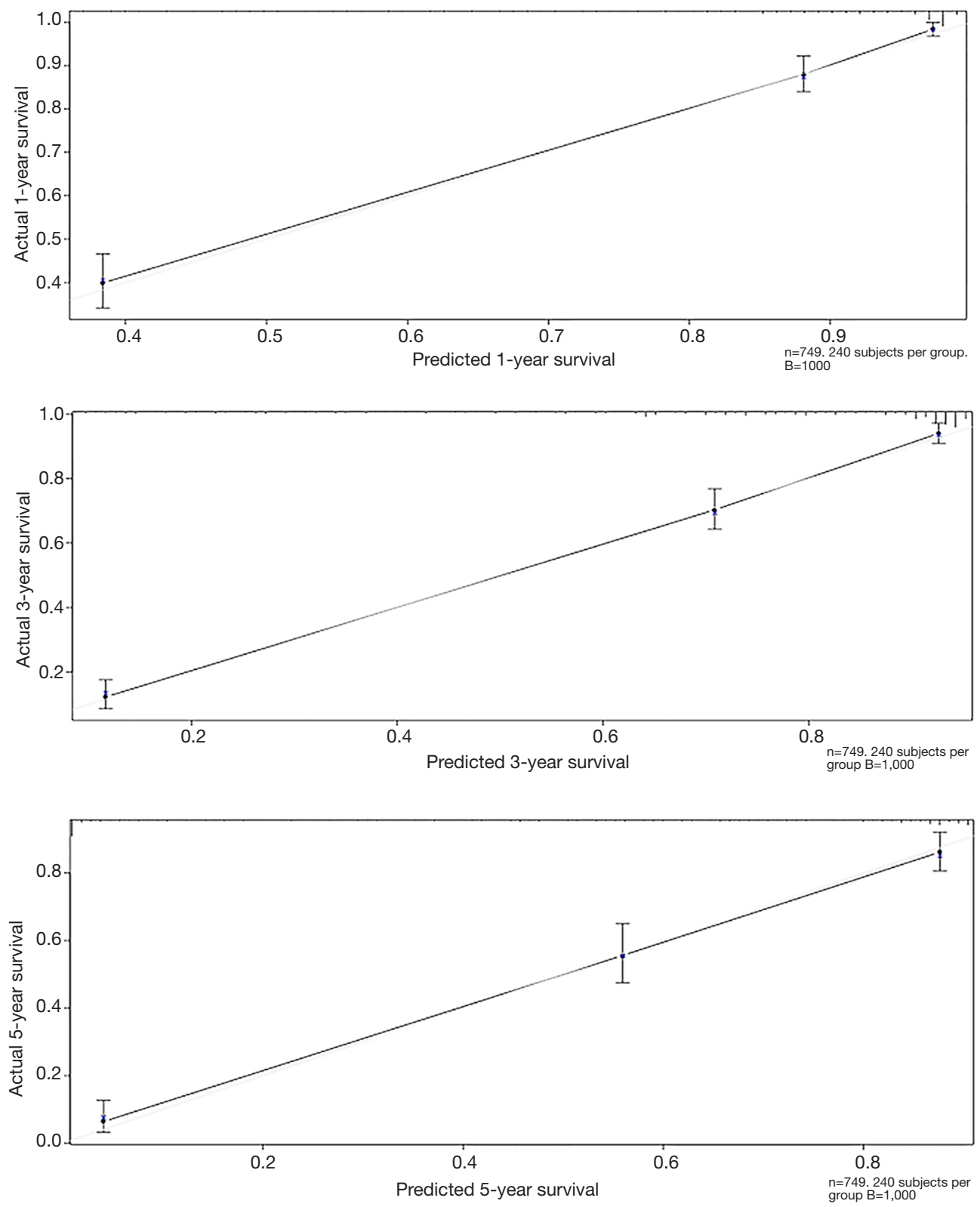

Figure 2 Calibration curve showing nomogram-predicted overall survival compared with the actual overall survival.

MRI. The PET/CT of colloid adenocarcinomas showed a relatively low SUVmax, which might cause higher rates of false-negative results (59-82\%) for malignant tumors (13). The possible reasons were as follows: (I) the tumors contained abundant mucus; (II) the metabolism of the tumors was relatively slow (14). We should combine other methods of examination and the history of present illness to make a preliminary clinical diagnosis to reduce the false negative rate of PET/CT. Because of the abundant amount of mucus and few malignant cells in the tumor, it was difficult to diagnose colloid adenocarcinoma by biopsy and most patients required surgical resection for the diagnosis. Histologically, it was difficult somewhile to separate colloid adenocarcinoma of lung from invasive mucinous adenocarcinoma of the lung. In colloid adenocarcinoma, the majority of tumors were made up of mucin pools which could cause an expansive alveolar cavity with the destruction of their walls and tumor cells were partly arranged in the alveolar wall. Some scattered tumor cells were in the mucous cell pool. Compared with 

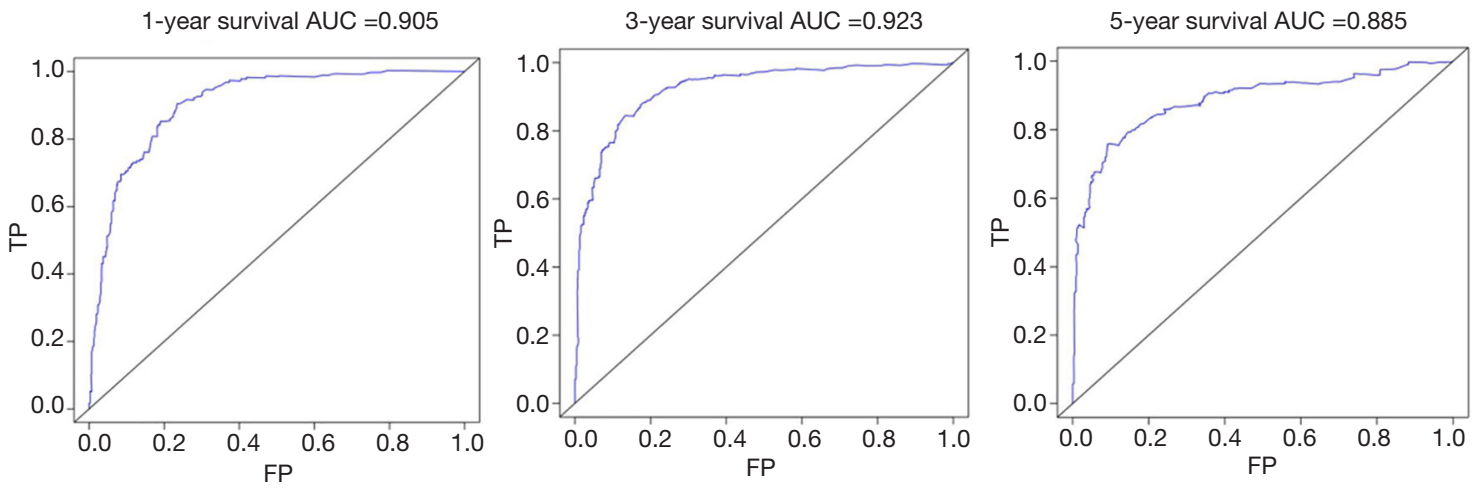

Footnotes: TP, true positive; FP, false positive

Figure 3 Discrimination plot. The AUC for the ROC were 0.905, 0.923, 0.885 respectively. AUC, area under the curve; ROC, receiver operating characteristic.
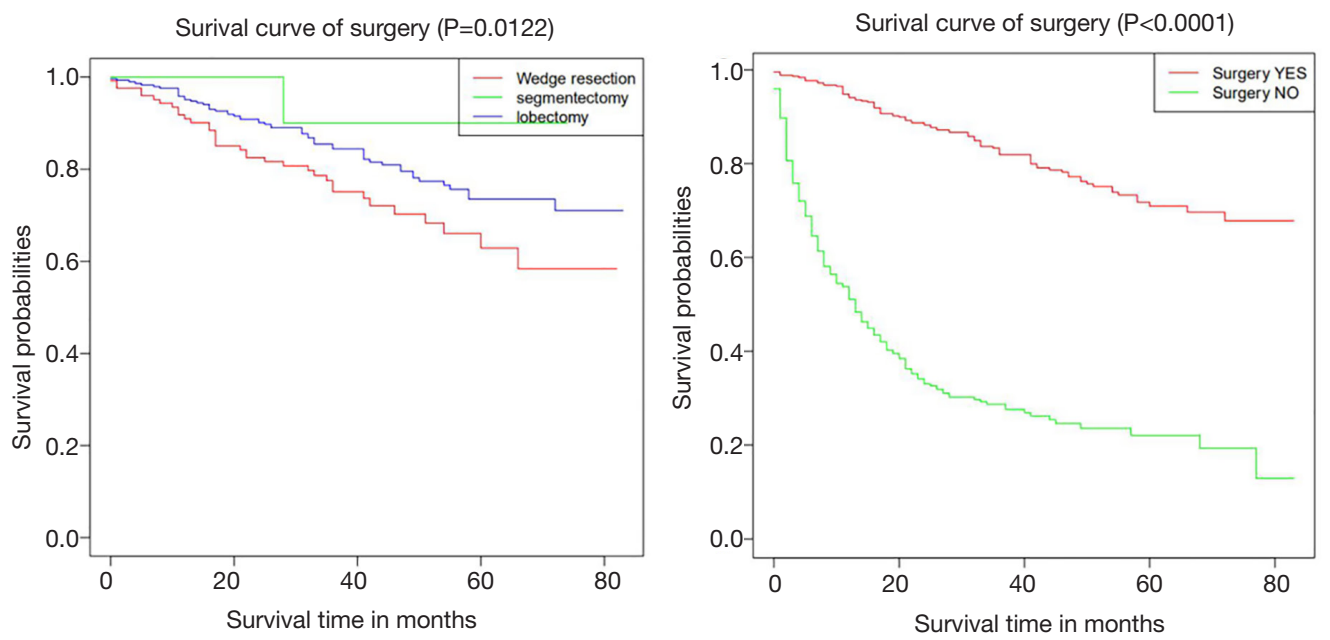

Figure 4 Kaplan-Meier curves of overall survival for patients in the different surgical status.

colloid adenocarcinoma, the most common patterns of growth in invasive mucinous adenocarcinoma were acinar, lepidic, micropapillary, papillary, and solid. By using clustering analysis, a genetic trait of mucin-producing lung adenocarcinoma demonstrated that the intermediate and distal respiratory bronchioles might be the origin of colloid adenocarcinoma of lung cancer (15). The reported studies showed the HNF4-A activated the CDX2 (16). The study of Maeda $\mathrm{Y}$ indicated that the result of the HNF4-A activated the CDX2 might make progenitor cells differentiate into mucous cells (17). Microscopically, colloid adenocarcinoma consists of two types of tumor cells are found floating in mucin pools: tall columnar goblet cells or signet ring cells. Goblet cell-type mucinous adenocarcinoma is generally stained positive with intestinal-type markers, such as
CK20, CDX2 and MUC2, while also positive for CK7 and TTF-1. Signet ring cell-type mucinous adenocarcinoma is immunoreactive for markers of pulmonary origin, such as TTF-1, CK7, and negative for CK20, CDX2 and MUC2.

In our study, the results of the Cox regression analysis showed that male patients over the age of 70 had relatively poor survival. The reasons are that men are more likely to smoke than women, and smoking can have an adverse effect on the prognosis of patients. The function of various organs of the body will be significantly reduced when patients are over 70 years old. The increase of complications and treatment-related complications in elderly patients often makes the elderly unable to successfully complete treatment or abandon treatment, thus affecting the survival time of the elderly. Compare with the upper lobe, middle lobe and 
other lobe had relatively poor survival. The perhaps reason was that lymph node metastasis which could cause poor survival was more common in the middle lobe and other lobe than in the upper lobe. Kalhor reported that the stage of colloid adenocarcinoma might influence the prognosis of the patients and there was only some KRAS without EGFR and ALK mutation (18). Targeted therapy is currently not available for KRAS mutation patients, MEK inhibitors (trametinib) and KRAS G12C inhibitors (AMG510, MRTX849) are used in clinical trials. Our study also generally showed that the higher the stage, the worse the prognosis. In a follow-up study of Oka et al., which included 13 patients of colloid adenocarcinoma, the results showed that there was a better prognosis in the primary tumors with diameters $\leq 3 \mathrm{~cm}$. The larger the tumor, the greater the risk of recurrence and intrapulmonary metastasis (19). Our study showed that only the $\mathrm{T} 2 \mathrm{~b}$ had a poor prognosis than T1 with statistically significant. This suggests that the size of the tumor may not be strongly related to the prognosis. Compared to other adenocarcinomas of the lung, the reason might be that colloid adenocarcinoma exhibited an indolent clinical behavior (20). In terms of treatment, surgery was still the main treatment for colloid adenocarcinoma, which could improve survival in our study. Russell et al. estimated the 5 -year survival to be $51 \%$ in 9 patients with pulmonary colloid adenocarcinoma who underwent surgical resection (21). Takao et al. also showed that if colloid adenocarcinoma was localized, complete surgical resection could improve the prognosis compared with other adenocarcinomas of the lung (22). Among surgical procedures, segmentectomy offered the best prognosis followed by lobectomy coupled with systematic lymph node dissection. The number of patients with segmentectomy was small, which might lead to certain statistical differences. Rossi et al. also showed that patients with CDX2-/MUC2positive expression than in those with CDX2-/MUC2negative expression tended to have a better prognosis (1).

There still were some several limitations that deserve attention in our study. First of all, it was a retrospective study that had an inescapable confounding bias. Second, the details of chemotherapy and radiotherapy were not obtained in the SEER database, which hindered further prognostic analyses. Third, the population of our study was patients in America, which cannot represent the global population. Finally, because the external validation was not accomplished, the proposed nomogram needed to be replicated and validated before it can be widely applied in clinical practice.

\section{Conclusions}

In conclusion, age, sex, race, primary site, tumor staging, stage $T$, metastatic sites, surgical treatment were associated with patients' survival. We constructed and validated a novel nomogram with relatively good accuracy to help predict 1-, 2- and 5-year overall survival for colloid adenocarcinoma. Clinicians could predict individualized survival and given treatment recommendations by using the prognostic model.

\section{Acknowledgments}

We thank Steven Wong for providing language editing assistance in this study.

Funding: None.

\section{Footnote}

Reporting Checklist: The authors have completed the TRIPOD reporting checklist. Available at http://dx.doi. org/10.21037/tcr-20-2795

Conflicts of Interest: Both authors have completed the ICMJE uniform disclosure form (available at http://dx.doi. org/10.21037/tcr-20-2795). The authors have no conflicts of interest to declare.

Ethical Statement: The authors are accountable for all aspects of the work in ensuring that questions related to the accuracy or integrity of any part of the work are appropriately investigated and resolved. The study was conducted in accordance with the Declaration of Helsinki (as revised in 2013). This article does not contain any studies with human participants or animals performed by any of the authors. All procedures performed in study involving human data were extracted freely from the SEER Research Data available to the public online (https://seer.cancer.gov/ data/access.html).

Open Access Statement: This is an Open Access article distributed in accordance with the Creative Commons Attribution-NonCommercial-NoDerivs 4.0 International License (CC BY-NC-ND 4.0), which permits the noncommercial replication and distribution of the article with the strict proviso that no changes or edits are made and the original work is properly cited (including links to both the formal publication through the relevant DOI and the license). See: https://creativecommons.org/licenses/by-nc-nd/4.0/. 


\section{References}

1. Rossi G, Murer B, Cavazza A, et al. Primary mucinous (socalled colloid) carcinomas of the lung: a clinicopathologic and immunohistochemical study with special reference to CDX-2 homeobox gene and MUC2 expression. Am J Surg Pathol 2004;28:442-52.

2. Travis WD, Brambilla E, Noguchi M, et al. International association for the study of lung cancer/American Thoracic Society/European Respiratory Society International Multidisciplinary Classification of lung adenocarcinoma. J Thorac Oncol 2011;6:244-85.

3. Roux FJ, Lantuéjoul S, Brambilla E, et al. Mucinous cystadenoma of the lung. Cancer 1995;76:1540-4.

4. Papla B, Malinowski E, Harazda M. Pulmonary mucinous cystadenoma of borderline malignancy. A report of two cases. Pol J Pathol 1996;47:87-90.

5. Higashiyama M, Doi O, Kodama K, et al. Cystic mucinous adenocarcinoma of the lung. Two cases of cystic variant of mucus-producing lung adenocarcinoma. Chest 1992;101:763-6.

6. Graeme-Cook F, Mark EJ. Pulmonary mucinous cystic tumors of borderline malignancy. Hum Pathol 1991;22:185-90.

7. Dixon AY, Moran JF, Wesselius LJ, et al. Pulmonary mucinous cystic tumor. Case report with review of the literature. Am J Surg Pathol 1993;17:722-8.

8. Ishibashi H, Moriya T, Matsuda Y, et al. Pulmonary mucinous cystadenocarcinoma: report of a case and review of the literature. Ann Thorac Surg 2003;76:1738-40.

9. Davison AM, Lowe JW, Da Costa P. Adenocarcinoma arising in a mucinous cystadenoma of the lung. Thorax 1992;47:129-30.

10. Edge SB, Compton CC. The American Joint Committee on Cancer: the 7th edition of the AJCC cancer staging manual and the future of TNM. Ann Surg Oncol 2010;17:1471-4.

11. Ogusu S, Takahashi K, Hirakawa H, et al. Primary Pulmonary Colloid Adenocarcinoma: How Can We Obtain a Precise Diagnosis? Intern Med 2018;57:3637-41.

12. Tateishi U, Müller NL, Johkoh T, et al. Mucin-producing adenocarcinoma of the lung: thin-section computed tomography findings in 48 patients and their effect on prognosis. J Comput Assist Tomogr 2005;29:361-8.

13. Murakami S, Saito H, Karino F, et al. ${ }^{18} \mathrm{~F}$-fluorodeoxyglucose uptake on positron emission tomography in mucinous adenocarcinoma. Eur J Radiol 2013;82:e721-5.

14. Sung YM, Lee KS, Kim BT, et al. Lobar mucinous bronchioloalveolar carcinoma of the lung showing negative FDG uptake on integrated PET/CT. Eur Radiol 2005;15:2075-8.

15. Sonzogni A, Bianchi F, Fabbri A, et al. Pulmonary adenocarcinoma with mucin production modulates phenotype according to common genetic traits: a reappraisal of mucinous adenocarcinoma and colloid adenocarcinoma. J Pathol Clin Res 2017;3:139-52.

16. Boudreau F, Rings EH, van Wering HM, et al. Hepatocyte nuclear factor-1 alpha, GATA-4, and caudal related homeodomain protein $\mathrm{Cdx} 2$ interact functionally to modulate intestinal gene transcription. Implication for the developmental regulation of the sucrase-isomaltase gene. J Biol Chem 2002;277:31909-17.

17. Maeda Y, Tsuchiya T, Hao H, et al. Kras(G12D) and Nkx21 haploinsufficiency induce mucinous adenocarcinoma of the lung. J Clin Invest 2012;122:4388-400.

18. Kalhor N. Colloid carcinoma of the lung: Current views. Semin Diagn Pathol 2014;31:265-70.

19. Oka S, Hanagiri T, Uramoto H, et al. Surgical resection for patients with mucinous bronchioloalveolar carcinoma. Asian J Surg 2010;33:89-93.

20. Cha YJ, Shim HS, Han J, et al. Clinicopathologic analysis of 10 cases of pulmonary colloid adenocarcinoma and prognostic implication of invasive micropapillary component. Pathol Res Pract 2018;214:2093-8.

21. Russell PA, Wainer Z, Wright GM, et al. Does lung adenocarcinoma subtype predict patient survival?: A clinicopathologic study based on the new International Association for the Study of Lung Cancer/American Thoracic Society/European Respiratory Society international multidisciplinary lung adenocarcinoma classification. J Thorac Oncol 2011;6:1496-504.

22. Takao M, Takagi T, Suzuki H, et al. Resection of mucinous lung adenocarcinoma presenting with intractable bronchorrhea. J Thorac Oncol 2010;5:576-8.

Cite this article as: Zhang J, Liu D. A novel nomogram to predict the overall survival of patients with colloid adenocarcinoma of the lung. Transl Cancer Res 2021;10(2):759767. doi: $10.21037 /$ tcr-20-2795 